\title{
Role of Gamma Knife surgery in the treatment of intracranial dural arteriovenous fistulas
}

\author{
Clinical article
}

\author{
Shunya Hanakita, M.D., ${ }^{1}$ Tomoyuki Koga, M.D., Ph.D., ${ }^{1}$ Masahiro Shin, M.D., Ph.D., ${ }^{1}$ \\ Masaaki Shojima, M.D., Ph.D., ${ }^{1}$ Hiroshi Igaki, M.D., Ph.D., ${ }^{2}$ \\ and Nobuhito Saito, M.D., Ph.D. ${ }^{1}$
}

Departments of ${ }^{I}$ Neurosurgery and ${ }^{2}$ Radiology, University of Tokyo Hospital, Tokyo, Japan

\begin{abstract}
Object. The goal of this study was to assess the efficacy of Gamma Knife surgery (GKS) in the management of dural arteriovenous fistulas (dAVFs).

Methods. The authors performed a retrospective analysis of a group of 22 patients who underwent GKS for dAVFs at the University of Tokyo Hospital between 1991 and 2009. The patients underwent CT or MR imaging with contrast enhancement every 6 months after GKS; when obliteration of a dAVF was indicated by these images, patients also underwent angiography. Follow-up in these patients ranged from 12 months to 100 months (median 33 months) after GKS.

Results. Obliteration of the dAVF was confirmed by neuroimaging in 12 patients (55\%). According to a KaplanMeier analysis, obliteration rates for the dAVFs were $51 \%$ at 3 years and $80 \%$ at 5 years. The obliteration rate for lesions without cortical venous drainage (CVD) was $86 \%$, which was significantly higher than the rate for dAVFs with CVD $(47 \%)(p=0.007)$. Hemorrhage at presentation $(p=0.03)$, a target volume less than $1.5 \mathrm{~cm}^{3}(p=0.009)$, and Cognard Type III or IV dAVF ( $\mathrm{p}=0.005)$ were factors associated with a higher obliteration rate. Among 10 patients whose dAVFs were not obliterated by the initial GKS, 5 patients underwent additional treatment and complete obliteration was achieved in all. Relief of tinnitus was obtained in $5(83 \%)$ of 6 patients with transverse-sigmoid sinus dAVFs, and ophthalmic symptoms improved in $2(67 \%)$ of 3 patients with cavernous sinus dAVFs. No patient experienced interval hemorrhage or radiation-induced complications after treatment.

Conclusions. Gamma Knife surgery is a safe and effective treatment for dAVF. It can be a first line of therapy in the multidisciplinary treatment strategy for dAVFs, especially when significant morbidity is anticipated with other therapeutic options. One should be very careful about recommending GKS for patients harboring dAVFs with CVD because of the expected natural history of such a lesion and the possibility of other therapeutic options.

(http://thejns.org/doi/abs/10.3171/2012.7.GKS12967)
\end{abstract}

\section{KeY Words • Gamma Knife surgery • dural arteriorvenous fistula • stereotactic radiosurgery}

$\mathrm{G}$ AMma Knife surgery is widely accepted as an effective treatment option for a variety of brain disorders including brain neoplasms, vascular lesions, and functional disorders. ${ }^{14}$ Arteriovenous malformation is the most common vascular disorder treated by GKS, and there have been numerous reports regarding outcomes of GKS for large numbers of patients with AVMs. ${ }^{9,14,15,22,23}$ Intracranial dAVF is another cerebrovascular disorder that can cause devastating symptoms due to cerebral venous congestion or intracranial hemorrhage. . $^{1,4}$, 27-29 Surgery and endovascular intervention are usually applied as primary treatment modalities for this disease. ${ }^{11}$ Gamma Knife surgery has been performed on dAVFs that are difficult to treat using other treatment modali-

\footnotetext{
Abbreviations used in this paper: $\mathrm{AVM}=$ arteriovenous malformation; CVD = cortical venous drainage; $\mathrm{dAVF}=$ dural arteriovenous fistula; GKS = Gamma Knife surgery; MR-DS = magnetic resonance-digital subtraction.
}

ties. . $12,13,19,22,24,26,31$ Compared with AVMs, the angioarchitecture of dAVFs is more complex and is often difficult to fully understand. ${ }^{16,18,24,28}$ In addition, these lesions frequently require earlier radical treatment because of impending associated symptoms. ${ }^{4,8,29}$ It takes at least several months for complete obliteration of a fistula following GKS. ${ }^{17,18,26}$ Therefore, the role of GKS in the treatment of dAVF remains controversial, with an ongoing debate over whether it should be a first choice of treatment or only a last resort, as an alternative to endovascular treatment or resection. ${ }^{5,12,13,19,22,24,26,31}$

In the present study we analyzed outcomes of GKS for dAVFs, and in this report we discuss the role of GKS in the treatment of this disease.

\section{Methods}

\section{Patient Population}

Between July 1991 and December 2009, 22 patients 
harboring dAVFs were treated with GKS at the University of Tokyo Hospital. We retrospectively reviewed the medical records of these 22 patients. The internal review board of the University of Tokyo Hospital approved the study protocol, and written informed consent was obtained from all subjects prior to participation in this study. Diagnoses of the dAVFs were confirmed by performing cerebral angiography in combination with CT or MR imaging. The pattern of venous drainage was determined based on the Cognard and Borden systems. ${ }^{3,6}$

In general, at our institution endovascular treatment is the first line of treatment because it is less invasive than open surgical procedures and, with endovascular treatment, it is possible to obtain immediate obliteration of a $\mathrm{dAVF}$. However, if a dAVF is located at the venous sinus and involves critical cerebral venous drainage, surgery is deemed more appropriate. Radiosurgery can be selected as a first line of treatment when both surgery and endovascular treatment are not advisable, for instance, when the lesion is in a deep location or there are associated risks of damaging critical venous sinuses. Gamma Knife surgery is also recommended when other treatments have resulted in partial obliteration. Among the 22 patients enrolled in this study, 8 patients $(36 \%)$ were referred to our department for residual lesion following endovascular treatment and 2 patients $(9 \%)$ were referred after surgery combined with endovascular treatment. In the other 12 patients (55\%), GKS was the initial treatment.

\section{Radiosurgical Treatment}

After the Leksell stereotactic frame had been affixed to the patient's head, the patient underwent stereotactic imaging so that we could obtain precise information on the shape, volume, and 3-dimensional coordinates of the dAVF. Computed tomography or MR imaging was used in combination with biplanar angiography. Treatment planning was jointly performed by neurosurgeons and radiation oncologists using commercially available software. First-generation treatment-planning software (KULA, Elekta AB), with which prescribed dose planning was manually superimposed on imaging films, was used until September 1998. Advanced planning software (Leksell GammaPlan, Elekta AB), which enables the operator to display multiple images on the computer screen and simultaneously superimpose isodose lines on them, was used thereafter. Targeted areas were limited to sites of arteriovenous communication. On angiographic images obtained during early to late arterial phases, the sites at which dural arteries drain directly into the dural sinus were located and treated with more than 20 Gy. Followup clinical examinations were performed at our hospital or by referring physicians. Patients underwent CT or MR imaging with contrast enhancement every 6 months. Recently, MR-DS angiographic images were obtained to evaluate outcomes. Angiography was performed when these images strongly suggested obliteration of the dAVF. Despite recent progress in the development of less invasive imaging modalities such as MR imaging or MR angiography, ${ }^{20}$ it is still difficult to confirm obliteration of dAVFs reliably based solely on those imaging studies. Angiography remains the gold standard for revealing the precise angioarchitecture and flow pattern of dAVFs. ${ }^{5}$ Thus, after a certain period of time, we recommend that each lesion be evaluated with angiography not only to confirm obliteration of the fistula but also to consider additional therapeutic options for residual lesions.

Estimated obliteration rates were calculated using the Kaplan-Meier method. The Cox proportional hazard model was used for multivariate analyses to evaluate factors that potentially affected fistula obliteration among the pool of patients: age, sex, existence of CVD, hemorrhage at presentation, target volume, location of the fistula, treatment with stereotactic radiosurgery alone, and draining venous pattern. All statistical analyses were performed using JMP 9 software (SAS Institute Inc.).

\section{Results}

\section{Characteristics of Patients}

The clinical characteristics of all patients are summarized in Table 1. Follow-up in these patients ranged from 12 to 100 months (mean 35 months, median 33 months) after GKS. Patient age at the time of GKS ranged from 31 to 73 years (mean 57 years, median 60 years). The median target volume was $1.5 \mathrm{~cm}^{3}$ (range $0.1-9.5 \mathrm{~cm}^{3}$ ). Locations of treated dAVFs included the following: transverse-sigmoid sinus junction in 9 patients, falcotentorial region in 6 patients, cavernous sinus in 3 patients, middle fossa in 2 patients, and anterior fossa and superior sagittal sinus in 1 patient each. The initial symptoms included hemorrhage in 6 patients, tinnitus in 6 patients, and orbital congestion in 3 patients. At the time of GKS, 9 patients exhibited neurological deficits caused by past hemorrhage or prior treatment. Motor weakness was seen in 3 patients, diplopia in 3 patients, and disturbance of consciousness in 3 patients.

On angiographic images at the time of radiosurgical dose planning, CVD was evident in 15 patients. Among those cases with CVD, 8 patients underwent GKS as the initial treatment and 7 patients after failure of other treatment modalities. The maximum radiation dose ranged from 33 to $50 \mathrm{~Gy}$ (mean $40 \mathrm{~Gy}$, median $40 \mathrm{~Gy}$ ) and the margin dose ranged from 18 to $25 \mathrm{~Gy}$ (mean $21 \mathrm{~Gy}$, median $20 \mathrm{~Gy})$.

\section{Obliteration Rate of dAVFs After GKS}

Of the 22 patients, complete obliteration of the fistula (Fig. 1) was confirmed by angiography in 9 patients between 12 and 50 months (median 27 months) after GKS. In 3 patients, obliteration of the fistula with remarkable improvement in patients' symptoms was confirmed only by MR imaging and MR-DS angiography 19 to 43 months after GKS. Further angiographic evaluation was scheduled for 2 of these 3 patients. In 1 patient, angiographic confirmation was not obtained because the patient has a history of anaphylaxis in response to the contrast enhancement used during the initial angiography. The overall Kaplan-Meier projected obliteration rates of dAVFs after a single GKS session were $51 \%$ at 3 years and $80 \%$ at 5 years. The rates of fistula obliteration were not significantly different between the GKS-only group 
TABLE 1: Summary of 22 patients with dAVFs treated by GKS

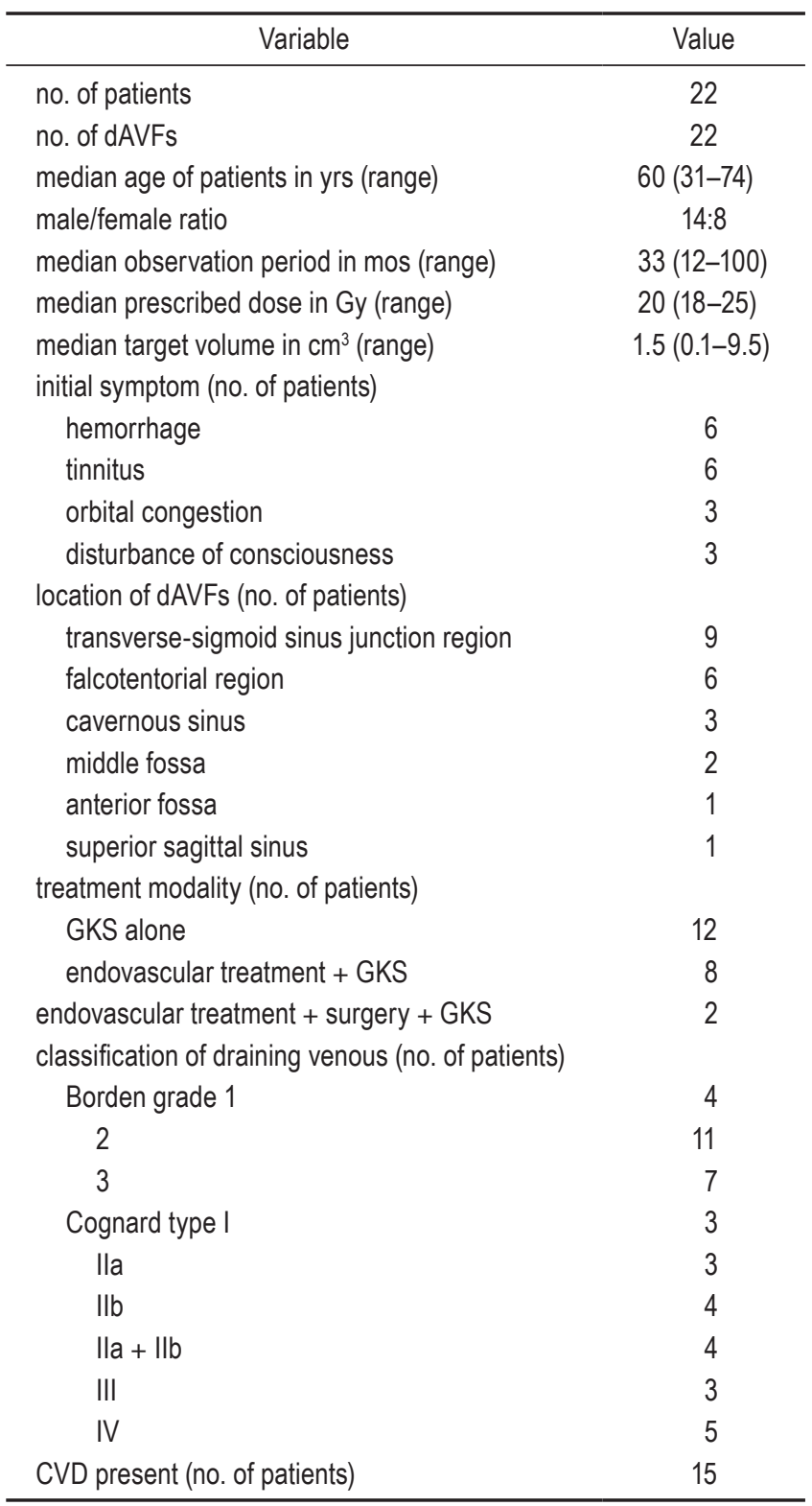

and the multimodal treatment group $(67 \%$ vs $40 \%, \mathrm{p}=$ 0.30, log-rank test).

In 15 patients who harbored dAVFs with CVD, complete obliteration of the fistula was apparent in 7 cases (47\%; $43 \%$ at 3 years and $43 \%$ at 5 years in the KaplanMeier projected obliteration rate). In contrast, in 7 patients with dAVFs without CVD, obliteration of the fistula was confirmed in 6 cases (total 86\%; 64\% at 3 years and $83 \%$ at 5 years in the Kaplan-Meier projected obliteration rate) - a significantly higher rate compared with those with CVD in a multivariate analysis $(p=0.007$, Table 2$)$. Other factors associated with a higher obliteration rate of dAVFs in the multivariate analysis were hemorrhage at presentation $(\mathrm{p}=0.03)$, target volume smaller than 1.5 $\mathrm{cm}^{3}(\mathrm{p}=0.009)$ and Cognard Type III or IV dAVF $(\mathrm{p}=$ $0.005)$. No statistical differences were found for patient

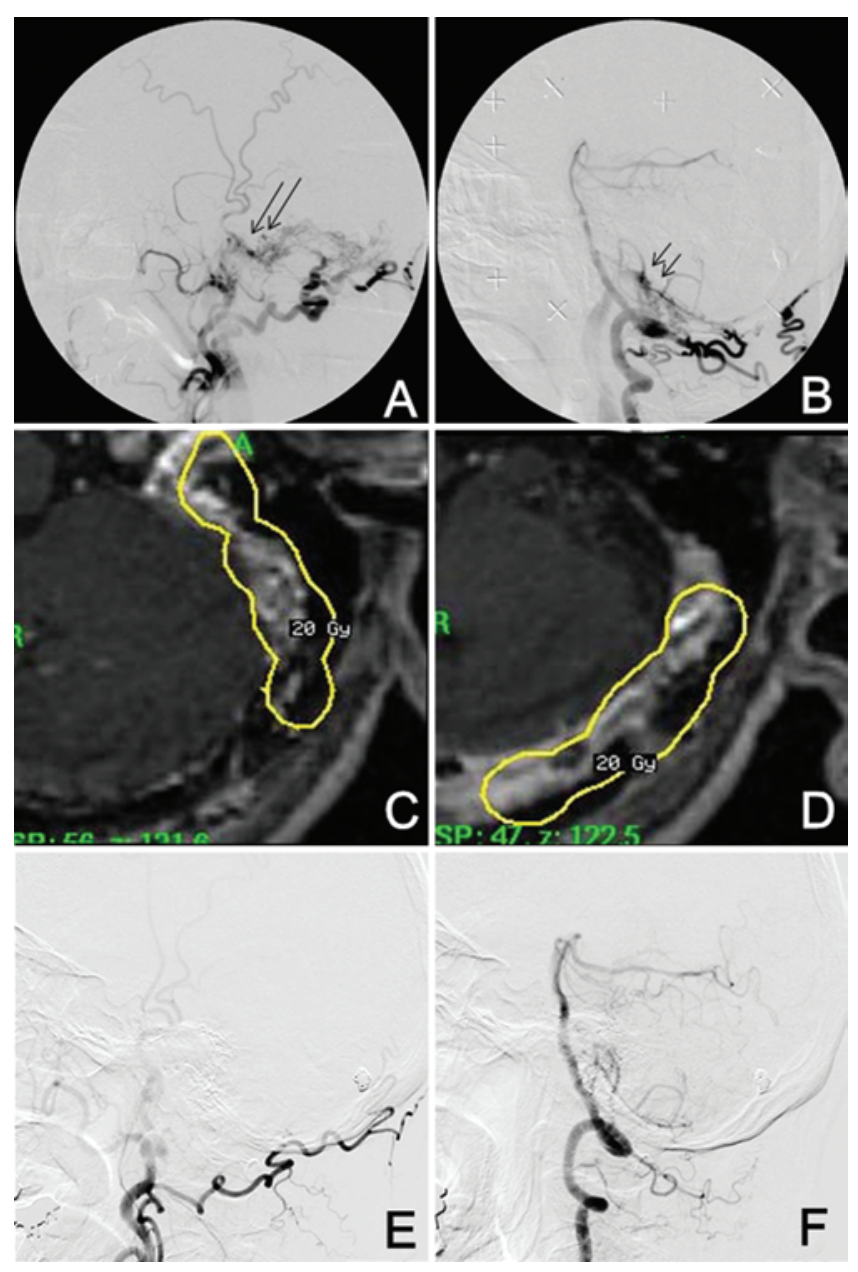

Fig. 1. A and B: Left external carotid artery (ECA) (A, lateral view) and left vertebral artery (VA) (B, lateral view) angiograms obtained before GKS, demonstrating a dAVF at the transverse-sigmoid sinus junction with an arterial supply from the left occipital artery (OA) (long arrows in A) and branches of the left VA (short arrows in B). C and D: Intraoperative contrast-enhanced axial MR images showing the dAVF in the region of the left transverse-sigmoid sinus junction. $\mathbf{E}$ and $\mathrm{F}$ : Left ECA and left VA angiograms demonstrating complete obliteration of the dAVF without neurological complication 40 months after GKS

age, sex, location of the lesion, and whether or not there was another previous treatment (Table 2).

In 10 patients, the residual fistula was evident on imaging studies 29 to 50 months (median 42 months) after GKS. Five of these patients underwent additional treatment, and obliteration of dAVF was achieved in all of them. One patient underwent a second GKS 38 months after the first treatment; and complete obliteration was confirmed 14 months after the second GKS (52 months after the initial one). In 2 patients, endovascular treatment was performed. In these 2 cases, the lesions were located at the transverse sinus and were accompanied by a diffuse arterial supply. Although these lesions did not disappear during the available follow-up period (44 months in 1 patient and 50 months in the other), the initial presenting symptom (tinnitus) resolved, and the fistula flow was reduced without any complication (Figs. 2 and 3). In both cases, the angioarchitecture of the dAVF became simpler 
TABLE 2: Factors associated with obliteration of the dAVF after GKS

\begin{tabular}{lll}
\hline \multicolumn{1}{c}{ Factor } & $\begin{array}{c}\text { Hazard Ratio }(95 \% \\
\text { Cl) (multivariate } \\
\text { analysis) }\end{array}$ & p Value \\
\hline patient age > 60 yrs & $1.06(0.23-5.75)$ & 0.94 \\
patient sex & $3.70(0.10-133.5)$ & 0.44 \\
lack of CVD & $29.7(2.29-951.4)$ & $0.007^{*}$ \\
hemorrhage at presentation & $28.7(0.0002-0.70)$ & $0.03^{*}$ \\
target volume < 1.5 cm ${ }^{3}$ & $40.5(2.13-7670)$ & $0.009^{*}$ \\
location at transverse-sigmoid sinus & $0.05(0.0008-1.45)$ & 0.08 \\
$\quad$ junction region & & \\
Cognard Type III or IV dAVF & $31.3(2.49-965)$ & $0.005^{*}$ \\
treated w/ GKS alone & $1.06(0.11-9.27)$ & 0.95 \\
\hline
\end{tabular}

* Significant at the level of $p<0.05$.

after the initial GKS, but no further response of radiosurgery was expected. In 1 patient, the residual fistula consisted of a very small fistula with relatively slow flow, which could be safely treated with a simple transarterial embolization 55 months after the initial GKS. In another case, the residual fistula became rather small 46 months after GKS, but it was still accompanied by CVD. That
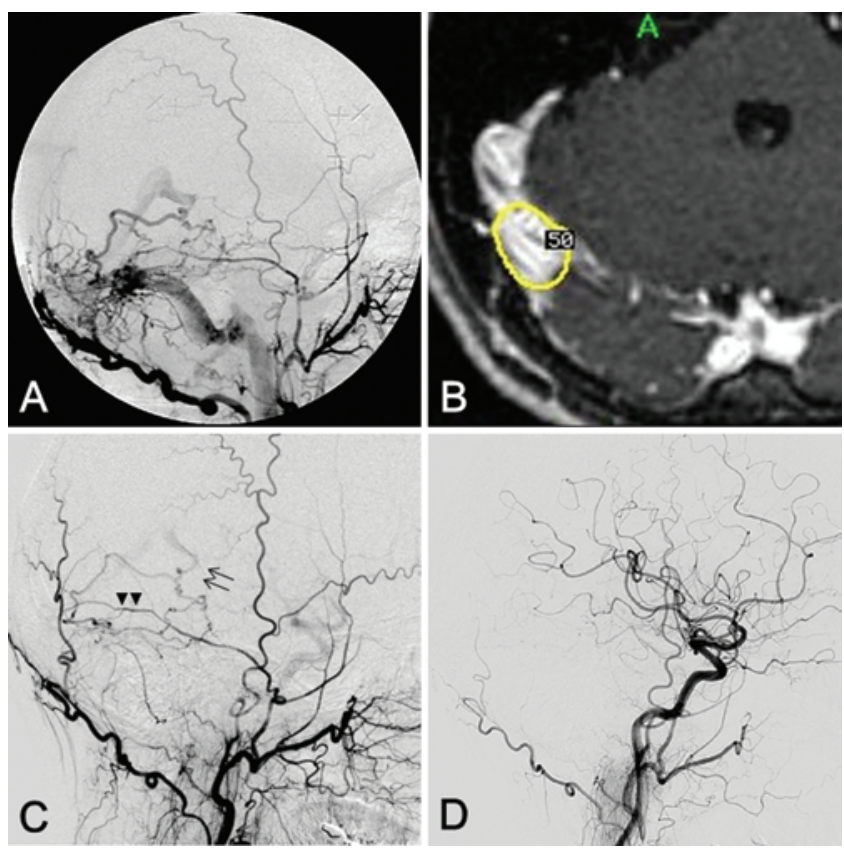

Fig. 2. $A$ and $B$ : Right $E C A$ angiogram $(A)$ and axial MR image (B) selected from the dose plan, revealing a dAVF in the region of the transverse sinus. A margin dose of $20 \mathrm{~Gy}$ was prescribed for a $1.7 \mathrm{~cm}^{3}$ region. C: Right ECA angiogram (lateral view) depicting a residual fistula fed by the middle meningeal artery (MMA) (arrowheads) and draining into the vein of Galen via the pial vein (arrows) 52 months after the initial stereotactic radiosurgery. This patient underwent endovascular treatment using transarterial embolization 55 months after the initial GKS. D: Right common carotid artery angiogram (lateral view) demonstrating complete disappearance of the lesion 7 months after the additional therapy.

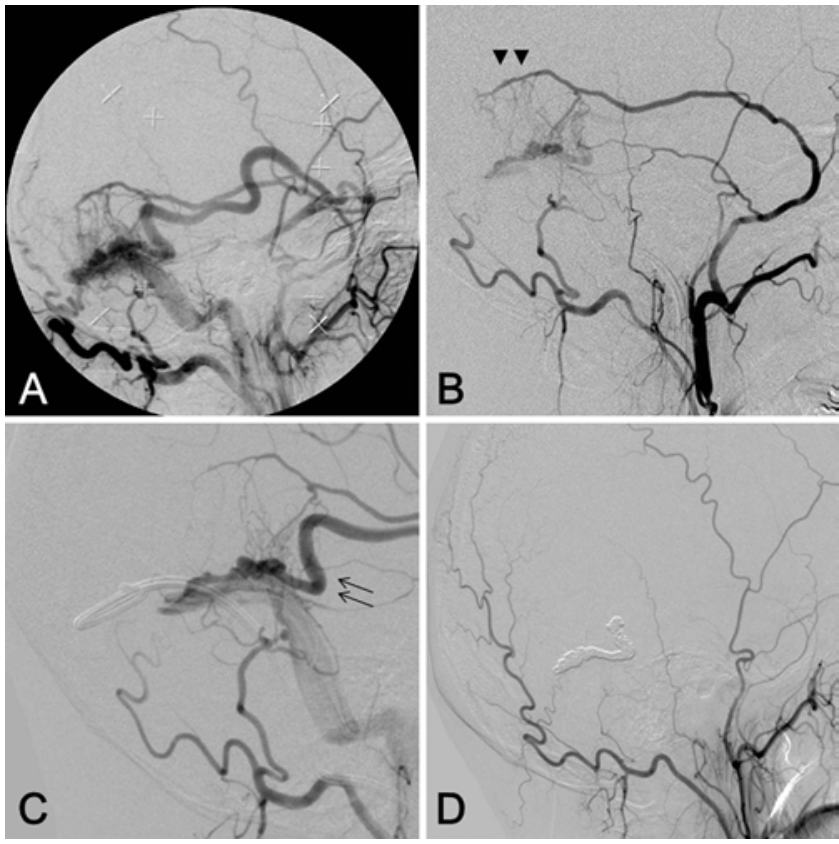

Fig. 3. Right ECA angiograms (lateral view). A: Angiogram revealing the transverse sinus dAVF with an arterial supply from the right OA and right MMA. This patient underwent radiosurgery alone. B: Angiogram depicting a residual lesion fed by the MMA (arrowheads) 44 months after treatment. C: Magnified angiogram. Following GKS, a reduction in flow from the arterial supply was achieved in this case, and the border between the transverse sinus and draining vein (arrows) was clearly defined. However, there was still cortical venous drainage. D: Angiogram demonstrating complete obliteration of the lesion 6 months after endovascular treatment was added to the therapeutic strategy (46 months after GKS).

patient was treated with transvenous embolization with the expectation of an earlier response. Complete obliteration was achieved in both patients. Another 2 patients underwent open resection, and complete obliteration of the dAVF was confirmed immediately after treatment in both of them.

No patient exhibited a latency interval hemorrhage after GKS.

We reviewed previous reports of radiosurgery using GKS for dAVFs and summarized the results in Table 3.

\section{Clinical Symptoms After GKS}

In 9 patients who initially presented with clinical symptoms associated with dAVF (tinnitus in 6 patients and chemosis in 3 patients), the symptoms resolved in 7 patients following GKS (5 patients with tinnitus and 2 patients with chemosis). In 2 patients, the clinical symptoms remarkably improved but remained persistent because of a residual dAVF. No patient exhibited radiation-induced neurological deterioration after GKS during the followup period.

\section{Discussion}

In this study, we found GKS to be safe and effective, achieving sufficient neurological improvement and a Kaplan-Meier projected obliteration rate of $80 \%$ at 5 


\section{S. Hanakita et al.}

TABLE 3: Results of GKS for dAVF in previous reports*

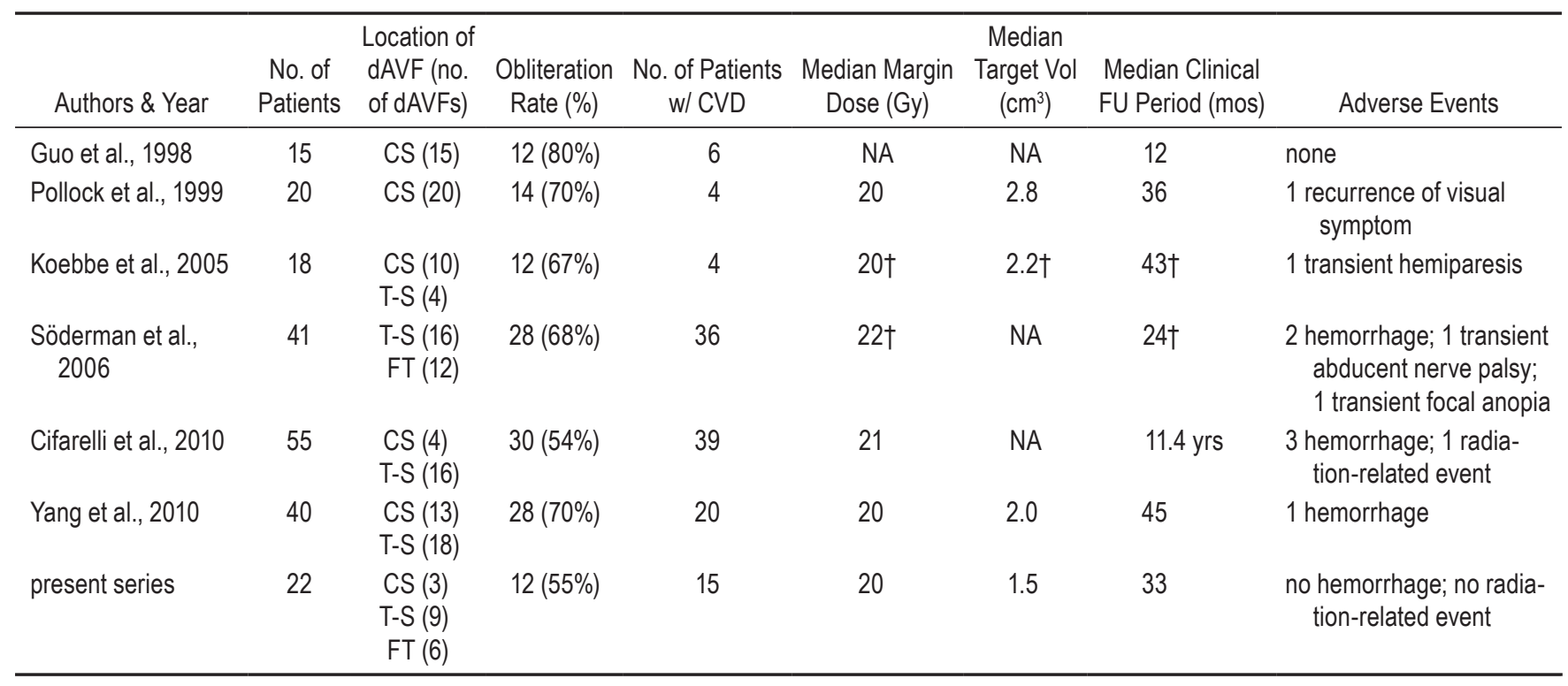

${ }^{*}$ CS = cavernous sinus; FT = falcotentorial region; FU = follow-up; NA = not available; T-S = transverse-sigmoid sinus junction.
$\dagger$ Mean value.

years. Higher obliteration rates could be expected without adverse events, especially in dAVFs with small volumes $(\mathrm{p}=0.009)$ and hemorrhage at presentation $(\mathrm{p}=0.03)$, which is in line with GKS for AVMs. ${ }^{25}$ Even if total obliteration was not achieved, in 2 of our cases a marked reduction of arteriovenous shunt flow resolved the patients' presenting symptoms and the angioarchitecture of the lesions was simplified, which facilitated additional endovascular treatment. These results suggest that GKS can be a first line of treatment in the multidisciplinary treatment strategy used for dAVFs when significant morbidity is expected to be associated with other therapeutic options because of the location of the lesion and the draining pattern, $5,19,24,26,30$ regardless of the history of hemorrhage.

It is true that, in addition to the benefits of GKS for the treament of dAVFs, there are some concerns we hold when we recommend this treatment to patients. During the last 2 decades, we have gradually learned a great deal about dAVFs, their natural history, and associated mechanisms that cause clinical symptoms. According to the literature, the risks of hemorrhage associated with dAVFs largely depend on the location and draining pattern of the fistula, the presence of CVD, and the galenic drainage. ${ }^{1,21,29}$ Among those factors, the presence of CVD on imaging studies is regarded to be an important sign, indicating very aggressive behavior on the part of the lesion, which requires early radical treatment. According to studies focused on hemorrhagic events, the annual risks of hemorrhage associated with dAVFs range from $3.7 \%$ to $8.9 \%, 4,8,26,28,29$ which are similar to those associated with intracranial AVMs. However, reported outcomes included patients who were treated only partially. When dAVFs with CVD presented with hemorrhage, the annual risk of hemorrhage was reported to range from $7.4 \%$ to $20 \% .^{4,27,28}$ Combined with the characteristics classified by Cognard
Type IV, the annual risk of a hemorrhagic event is raised to $27 \% .{ }^{4}$ To immediately abolish these risks, which are not negligible, endovascular intervention ${ }^{2,10,11,21}$ or resection to occlude a single draining route is recommended. ${ }^{7}$ According to previous reports, a latency period of at least 6 months follows GKS before obliteration of the fistula. ${ }^{18}$ Therefore, GKS can be a good choice of therapeutic option for a dAVF with CVD when other treatments could significantly reduce the impending risk of hemorrhage but could not achieve total obliteration of the dAVF.

\section{Conclusions}

Gamma Knife surgery is a safe and effective treatment modality for dealing with dAVFs. It can be a first line of treatment in the multidisciplinary treatment strategy for dAVFs, especially when significant morbidity is anticipated with other therapeutic options. If the dAVF is accompanied by CVD, we have to be very careful in recommending GKS for the patient, given the expected natural history of such lesions and the possibility of other therapeutic options.

\section{Disclosure}

The authors report no conflict of interest concerning the materials or methods used in this study or the findings specified in this paper.

Author contributions to the study and manuscript preparation include the following. Conception and design: Hanakita, Shin. Acquisition of data: Hanakita, Koga. Analysis and interpretation of data: Hanakita, Igaki. Drafting the article: Hanakita. Critically revising the article: all authors. Reviewed submitted version of manuscript: all authors. Approved the final version of the manuscript on behalf of all authors: Hanakita. Administrative/technical/material support: Koga, Igaki. Study supervision: Koga, Shin, Shojima, Igaki, Saito. 


\section{References}

1. Awad IA, Little JR, Akarawi WP, Ahl J: Intracranial dural arteriovenous malformations: factors predisposing to an aggressive neurological course. J Neurosurg 72:839-850, 1990

2. Bavinzski G, Richling B, Killer M, Gruber A, Levy D: Evolution of different therapeutic strategies in the treatment of cranial dural arteriovenous fistulas-report of 30 cases. Acta Neurochir (Wien) 138:132-138, 1996

3. Borden JA, Wu JK, Shucart WA: A proposed classification for spinal and cranial dural arteriovenous fistulous malformations and implications for treatment. J Neurosurg 82:166179,1995

4. Bulters DO, Mathad N, Culliford D, Millar J, Sparrow OC: The natural history of cranial dural arteriovenous fistulae with cortical venous reflux - the significance of venous ectasia. Neurosurgery 70:312-319, 2012

5. Cifarelli CP, Kaptain G, Yen CP, Schlesinger D, Sheehan JP: Gamma knife radiosurgery for dural arteriovenous fistulas. Neurosurgery 67:1230-1235, 2010

6. Cognard C, Gobin YP, Pierot L, Bailly AL, Houdart E, Casasco A, et al: Cerebral dural arteriovenous fistulas: clinical and angiographic correlation with a revised classification of venous drainage. Radiology 194:671-680, 1995

7. da Costa LB, Terbrugge K, Farb R, Wallace MC: Surgical disconnection of cortical venous reflux as a treatment for Borden type II dural arteriovenous fistulae. Acta Neurochir (Wien) 149:1103-1108, 2007

8. Duffau H, Lopes M, Janosevic V, Sichez JP, Faillot T, Capelle L, et al: Early rebleeding from intracranial dural arteriovenous fistulas: report of 20 cases and review of the literature. $\mathbf{J}$ Neurosurg 90:78-84, 1999

9. Flickinger JC, Kondziolka D, Lunsford LD, Pollock BE, Yamamoto M, Gorman DA, et al: A multi-institutional analysis of complication outcomes after arteriovenous malformation radiosurgery. Int J Radiat Oncol Biol Phys 44:67-74, 1999

10. Friedman JA, Pollock BE, Nichols DA, Gorman DA, Foote RL, Stafford SL: Results of combined stereotactic radiosurgery and transarterial embolization for dural arteriovenous fistulas of the transverse and sigmoid sinuses. J Neurosurg 94:886-891, 2001

11. Gandhi D, Chen J, Pearl M, Huang J, Gemmete JJ, Kathuria S: Intracranial dural arteriovenous fistulas: classification, imaging findings, and treatment. AJNR Am J Neuroradiol 33: 1007-1013, 2012

12. Guo WY, Pan DH, Wu HM, Chung WY, Shiau CY, Wang LW, et al: Radiosurgery as a treatment alternative for dural arteriovenous fistulas of the cavernous sinus. AJNR Am J Neuroradiol 19:1081-1087, 1998

13. Koebbe CJ, Singhal D, Sheehan J, Flickinger JC, Horowitz M, Kondziolka D, et al: Radiosurgery for dural arteriovenous fistulas. Surg Neurol 64:392-399, 2005

14. Koga T, Shin M, Saito N: Role of gamma knife radiosurgery in neurosurgery: past and future perspectives. Neurol Med Chir (Tokyo) 50:737-748, 2010

15. Koga T, Shin M, Terahara A, Saito N: Outcomes of radiosurgery for brainstem arteriovenous malformations. Neurosurgery 69:45-52, 2011

16. Lewis AI, Tomsick TA, Tew JM Jr: Management of tentorial dural arteriovenous malformations: transarterial embolization combined with stereotactic radiation or surgery. $\mathbf{J}$ Neurosurg 81:851-859, 1994

17. Link MJ, Coffey RJ, Nichols DA, Gorman DA: The role of radiosurgery and particulate embolization in the treatment of dural arteriovenous fistulas. J Neurosurg 84:804-809, 1996

18. Loumiotis I, Lanzino G, Daniels D, Sheehan J, Link M: Radiosurgery for intracranial dural arteriovenous fistulas (DAVFs): a review. Neurosurg Rev 34:305-315, 2011
19. Maruyama K, Shin M, Kurita H, Tago M, Kirino T: Stereotactic radiosurgery for dural arteriovenous fistula involving the superior sagittal sinus. Case report. J Neurosurg 97 (5 Suppl):481-483, 2002

20. Meckel S, Maier M, Ruiz DS, Yilmaz H, Scheffler K, Radue EW, et al: MR angiography of dural arteriovenous fistulas: diagnosis and follow-up after treatment using a time-resolved 3D contrast-enhanced technique. AJNR Am J Neuroradiol 28:877-884, 2007

21. Natarajan SK, Ghodke B, Kim LJ, Hallam DK, Britz GW, Sekhar LN: Multimodality treatment of intracranial dural arteriovenous fistulas in the Onyx era: a single center experience. World Neurosurg 73:365-379, 2010

22. Pollock BE, Nichols DA, Garrity JA, Gorman DA, Stafford SL: Stereotactic radiosurgery and particulate embolization for cavernous sinus dural arteriovenous fistulae. Neurosurgery 45:459-467, 1999

23. Sasaki T, Kurita H, Saito I, Kawamoto S, Nemoto S, Terahara A, et al: Arteriovenous malformations in the basal ganglia and thalamus: management and results in 101 cases. J Neurosurg 88:285-292, 1998

24. Shin M, Kurita H, Tago M, Kirino T: Stereotactic radiosurgery for tentorial dural arteriovenous fistulae draining into the vein of Galen: report of two cases. Neurosurgery 46:730 734,2000

25. Shin M, Maruyama K, Kurita H, Kawamoto S, Tago M, Terahara A, et al: Analysis of nidus obliteration rates after gamma knife surgery for arteriovenous malformations based on longterm follow-up data: the University of Tokyo experience. $\mathbf{J}$ Neurosurg 101:18-24, 2004

26. Söderman M, Edner G, Ericson K, Karlsson B, Rähn T, Ulfarsson E, et al: Gamma knife surgery for dural arteriovenous shunts: 25 years of experience. J Neurosurg 104:867875,2006

27. Söderman M, Pavic L, Edner G, Holmin S, Andersson T: Natural history of dural arteriovenous shunts. Stroke 39:17351739,2008

28. Strom RG, Botros JA, Refai D, Moran CJ, Cross DT III, Chicoine MR, et al: Cranial dural arteriovenous fistulae: asymptomatic cortical venous drainage portends less aggressive clinical course. Neurosurgery 64:241-248, 2009

29. van Dijk JM, terBrugge KG, Willinsky RA, Wallace MC: Clinical course of cranial dural arteriovenous fistulas with long-term persistent cortical venous reflux. Stroke 33:12331236, 2002

30. Wu HM, Pan DH, Chung WY, Guo WY, Liu KD, Shiau CY, et al: Gamma Knife surgery for the management of intracranial dural arteriovenous fistulas. J Neurosurg 105 Suppl:43-51, 2006

31. Yang HC, Kano H, Kondziolka D, Niranjan A, Flickinger JC, Horowitz MB, et al: Stereotactic radiosurgery with or without embolization for intracranial dural arteriovenous fistulas. Neurosurgery 67:1276-1285, 2010

Manuscript submitted May 15, 2012.

Accepted July 18, 2012.

Findings from this study were presented in abstract form at the 16th International Meeting of the Leksell Gamma Knife Society, Sydney, Australia, March 2012.

Please include this information when citing this paper: DOI: 10.3171/2012.7.GKS12967.

Address correspondence to: Shunya Hanakita, M.D., Department of Neurosurgery, University of Tokyo Hospital, 7-3-1 Hongo, Bunkyo-ku, Tokyo 113-8655, Japan.email: hanakita-s@umin.ac.jp. 